\title{
U. S. Geological Survey
}

OREN FIEE REPORT 79-368

This report is preliminary and has

not been edited or reviewer for

conformity with Ceolcrical survey

standards or nomeaclature.

LANDSAT LINEAMENTS IN PARTS OF WEST VIRGINIA, KENTUCKY, OHIO, AND VIRGINIA

$$
\text { by }
$$

George W. Colton

NOTES

The Landsat MSS (Multispectral Scanner) images used were processed by the Image Processing Facility, U.S. Geological Survey,

Flagstaff, AZ, under the supervision of Pat Chavez, Jr. All frames are high-pass filtered black and white versions of band six. They were further enhanced by removing noise patterns, by applying a linear contrast stretch and by lessening the effects of atmospheric haze. The high pass filter and contrast stretch enhance high frequency tonal differences (those occurring within small areas) so that fine details of topographic relief are made more apparent. In addition, a correction was applied to make the sun angle more uniform across the area of the Appalachian basin and the frames were geometrically rectified for compatibility with standard 2-degree topographic sheets on the transverse Mercator projection: The working scale was 1:500,000. This map, an Albers equal area projection, is a rectified $0.5 \mathrm{x}$ reduction of the original compilation. 
As drawn, the length of each line marking a lineament is a direct measure of the length of the feature by which the lineament is expressed. Most of the lineaments shown are recognized primarily by topographic expression, and most commonly as aligned straight segments of two or more streams or small rivers. Only in the Valley and Ridge and Blue Ridge provinces are lineaments expressed primarily by recognized tonal differences. However, even these for the most part probably are vegetation patterns along small valleys whose relief is invisible at the resolution of the images. Those lineaments of uncertain structural significance are indicated by a question mark, which is positioned along that part of the line where most uncertainty exists. Where located at the middle of the line, the entire linear feature is considered to be in the uncertain category. 
I have tried to incorporate as little interpretation as possible. Only the longer or more conspicuous lineaments from among many thousands were selected for this map. By far the largest and most conspicuous linear features in the area of the map are those resulting primarily from folding and thrust faulting in the Valley and Ridge province. These are not shown. However, several mapped cross-cutting faults are shown (as they are visibly expressed on the images) and are identified by the letter symbols below. The Coeburn fault is a gentle graben composed of many closely spaced normal faủlts of small displacement. The parallel but shorter line 6 miles to the west is a similar graben.

*B.B.C.F. = Bishop-Bradshaw Creek fault of Elder and others (1974). Also the Canbrake fault of Johnston and others (1975). R.F.F. = Russell Fork fault. CO.F. = Coeburn fault of Johnston and others (1975). 